Sādhanā Vol. 29, Part 5, October 2004, pp. 477-497. ( $)$ Printed in India

\title{
A stochastic dynamic programming model for stream water quality management
}

\author{
P P MUJUMDAR and PAVAN SAXENA \\ Department of Civil Engineering, Indian Institute of Science, Bangalore 560012 , \\ India \\ e-mail: pradeep@civil.iisc.ernet.in
}

MS received 12 November 2003; revised 27 April 2004

\begin{abstract}
This paper deals with development of a seasonal fraction-removal policy model for waste load allocation in streams addressing uncertainties due to randomness and fuzziness. A stochastic dynamic programming (SDP) model is developed to arrive at the steady-state seasonal fraction-removal policy. A fuzzy decision model (FDM) developed by us in an earlier study is used to compute the system performance measure required in the SDP model. The state of the system in a season is defined by streamflows at the headwaters during the season and the initial DO deficit at some pre-specified checkpoints. The random variation of streamflows is included in the SDP model through seasonal transitional probabilities. The decision vector consists of seasonal fraction-removal levels for the effluent dischargers. Uncertainty due to imprecision (fuzziness) associated with water quality goals is addressed using the concept of fuzzy decision. Responses of pollution control agencies to the resulting end-of-season DO deficit vector and that of dischargers to the fraction-removal levels are treated as fuzzy, and modelled with appropriate membership functions. Application of the model is illustrated with a case study of the Tungabhadra river in India.
\end{abstract}

Keywords. Fuzzy decision; stochastic optimization; water quality; streamflow.

\section{Introduction}

River water quality management problems are characterized by various uncertainties at different stages of decision making to arrive at optimal allocation of the assimilative capacity of the river system. The two types of uncertainties that prominently influence decision making are uncertainty due to randomness and that due to imprecision or subjectivity. Problems of decision making for utilizing the assimilative capacity of a river without adversely affecting the water quality are addressed by waste load allocation (WLA) models. A WLA model generally comprises three components: (i) a multiobjective optimisation model representing goals and constraints of the water quality management problem; (ii) a water quality simulation model that provides spatial transport of the water quality constituents in the river system and (iii) models for addressing uncertainty in the system. The two sets of objectives normally considered in WLA models deal with maximizing the water quality in the streams, which reflects 
the goal of the pollution control agency (PCA), and minimizing the waste treatment cost to be borne by the effluent dischargers such as industries and municipal bodies. These two sets of objectives are often in conflict with each other. Due to seasonal variation of river flow, the assimilative capacity of the river system also varies within a year. A seasonal fraction-removal policy has to be specified based on varying assimilative capacity of the river rather than on a single value of river flow for the entire year. Seasonal waste water discharge programmes employ different effluent standards during different times of the year to take advantage of the variation in receiving water susceptibility to adverse conditions.

The problem of seasonal fraction-removal of effluent discharges in the streams has been addressed by many researchers. Rossman (1989) developed a seasonal waste load allocation model to achieve the maximum economic benefits without violating water quality standards. This model describes an approach for designing risk equivalent seasonal discharge limits for single-discharger stream segments, where risk is defined as the probability of incurring one or more water quality violations in any given year. Lence et al (1990) developed risk equivalent seasonal discharge programs for multiple discharger system. This approach is similar to that of Rossman (1989), but it also accommodates river segments with several dischargers. Two management objectives are proposed as a surrogate for minimising the seasonally varying waste treatment effort: the minimum average uniform treatment and the maximum total discharge objective. The designed seasonal waste load allocation maintains risk equivalence with a nonseasonal waste discharge program and optimises one of these two objectives. Wotton \& Lence (1995) presented a modified seasonal waste discharge program for managing BOD and DO in river systems that have ice covers during certain periods of the year. The uniform treatment levels during the ice covered period are evaluated by simulating water quality based on reaeration coefficients that are nearly zero. Lence \& Takyi (1992) applied a modified regionalised sensitivity analysis for assessing the effect of unreliable stream records on the design of seasonal discharge programs. Uncertainty in flow and temperature data at different times in the year and at different locations in the stream is addressed in their work. They argue that the degree to which uncertain stream conditions affect the management model outcome depends on the water quality goals and the length of the seasons examined. To provide robustness to the water quality management models, Takyi and Lence (1996) used the Chebyshev criteria to develop direct regulation water quality management models that maximise excess water quality above the water quality goal at all check points along the river. Such models may be robust (in terms of achieving water quality) to uncertainties in input information. The methodology of simulation-optimisation has been used in some recent studies in the areas of surface water quality and quantity management (Dai \& Labadie 2001); and water quality management (Carmichael \& Strzepek 2000). A major issue that has been addressed in the WLA models is uncertainty due to randomness of variables that influence the decision making the most. There are three widely used methods for incorporating randomness into a water quality management model (Takyi \& Lence 1999). These are (i) chance-constrained optimisation (e.g. Loucks \& Lynn 1966, Lohani \& Thanh 1978, 1979, Burn \& McBean 1985, 1986, Ellis 1987, Fujiwara et al 1986, 1987); (ii) combined simulation-optimisation (e.g., Burn 1989, Takyi \& Lence 1994); and (iii) multiple realization based approach (e.g., Burn \& Lence 1992, Takyi \& Lence 1999). Another type of uncertainty prominent in the management of stream water quality is uncertainty due to imprecision or fuzziness associated with the goals related to water quality standards and pollutant abatement. Establishing minimum desirable and maximum permissible water quality criteria, and minimal pollutant treatment levels is often subjective and contains an element of imprecision. We (Sasikumar \& Mujumdar 1998, 2000, Mujumdar \& Sasikumar 2002) have addressed the uncertainty due to imprecision by a 
fuzzy optimization approach. A brief review of uncertainty concepts used in WLA problems is given in Mujumdar (2001).

As in many other fields of water resource decision making, optimisation models developed for water quality management decisions also remain largely restricted to the academic arena and have not found their way into practice in a significant way. In a discussion on models for reservoir system operations, Labadie (1997) speculated on some possible causes for the lack of acceptance and limited implementation of optimisation techniques. The same causes also may be attributed for lack of acceptance of water quality planning and management models for practical applications. Some of these are (i) decision makers are unwilling to accept models that use an unrealistic simplification of physics of the actual problem (e.g. a simplified BOD-DO model) in order to reach an optimal solution; (ii) most optimisation models are formulated in a way that do not adequately account for inherent uncertainty (e.g., goals and aspirations of PCA and dischargers) and, (iii) most applications would require customized program development since, in many cases generalized software packages are unavailable. This paper focuses on the second aspect, viz., addressing uncertainty. Two major forms of uncertainty - randomness and fuzziness - are integrated in the SDP model developed in the paper. Other general limitations mentioned above are still relevant to the work presented in this paper also.

Most SDP approaches developed for stream water quality management deal with variation in space i.e., along the length of the river, with a steady-state assumption on river and effluent flow. However the state of the system characterised by streamflow, effluent flow and ambient water quality conditions may change significantly across seasons randomly. Also, the state of the system changes spatially from reach to reach. A comprehensive optimisation model should therefore account for both temporal and spatial variations. In this paper, a SDP model is developed which carries out optimisation across seasons accounting for spatial variation of the river system.

\section{Model features}

Figure 1 shows the outline of the model.

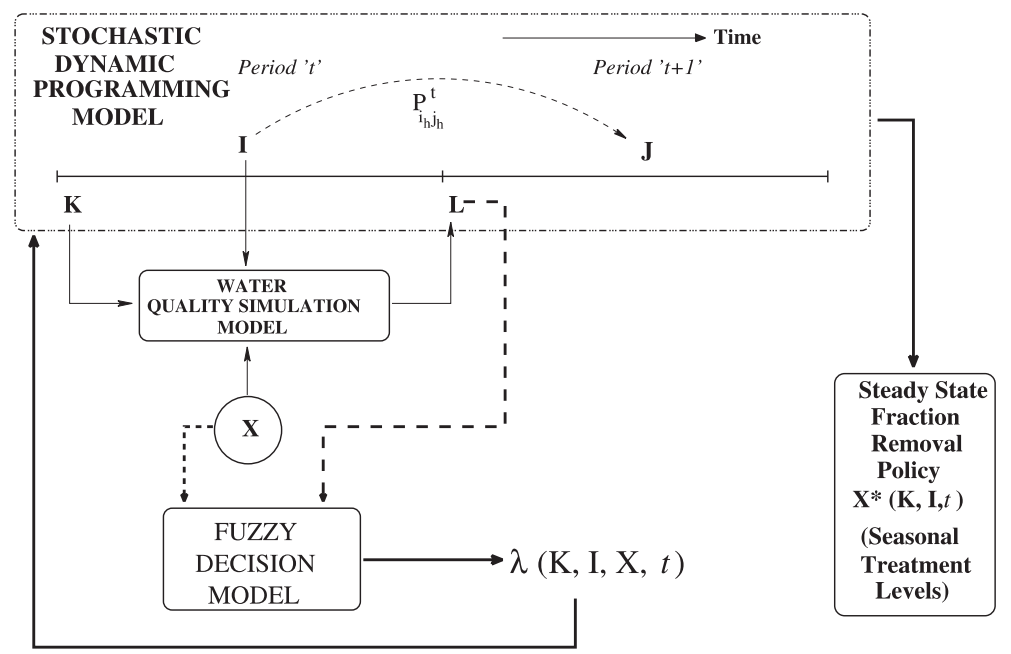

Figure 1. Schematic representation of the model. 
The stochastic dynamic programming (SDP) model, on solution, specifies the steady-state fraction-removal policy, for dischargers in a river system. Steady-state fraction-removal policy refers to optimal seasonal effluent treatment levels that should be applied every year for a given state of the system. A river system with randomly varying seasonal streamflow is considered in the model. The time horizon over which the decisions need to be made is taken as one year. Seasons are considered as stages. In each season, the possible state of streamflow is represented by a finite number of discrete flow values. Steady-state is assumed within a season. The state of the system is characterised by beginning-of-season DO deficit $\mathbf{K}$ at some pre-specified checkpoints, and streamflow during the season at the headwaters, I. The decision variables are the fraction-removal levels for the dischargers. The state transformation of the river system from the beginning-of-season DO deficit vector, $\mathbf{K}$, to the end-of-season DO deficit vector, $\mathbf{L}$, is obtained using a water quality simulation model, for a given set of fraction-removals. The desirable and the permissible concentration levels of the water quality indicators (e.g., DO deficit) are subjectively fixed by the decision makers. Specifications of these levels depends on the perceptions of the decision makers. These concentration levels are, in general, different for different pollutants and checkpoints. For modelling purpose, they can be generalised to be different for different seasons. This generalisation is necessary because the river water may be used for different purposes during different seasons, and therefore, the allowable and desirable levels of the water quality indicators could be quite different across the seasons.

Imprecision associated with the goals of the pollution control agencies and dischargers is addressed using the concept of fuzzy decision (Bellman \& Zadeh 1970). Response of pollution control agencies to the resulting end-of-season DO deficit vector, $\mathbf{L}$, and that of dischargers to the applied fraction-removal level vector, $\mathbf{X}$, are treated as fuzzy. A fuzzy decision model (FDM) (Sasikumar \& Mujumdar 1998) is used to compute the system performance measure required for the SDP model. The output of the fuzzy decision model is the fuzzy decision corresponding to the goals of PCA and dischargers for a given state of the system. This fuzzy decision is used in the SDP model to obtain optimal seasonal fraction-removal levels.

\section{Stochastic dynamic programming (SDP) model}

In this section, details of the stochastic dynamic programming (SDP) model to derive the steady-state fraction-removal policy are discussed. System performance values associated with a given state of the system required in the SDP model for a specified set of fractionremoval levels are provided by a second level, fuzzy optimization model. The state of the system in a season is defined by head water flow during a season and initial DO deficits at the check points. The random nature of the streamflows is addressed through the seasonal transition probabilities, assuming the seasonal streamflow to follow a one-step Markov Chain. A steady-state water quality simulation model provides the system response to a given pollutant loading from point sources.

\subsection{Description of the river system}

A general river system as shown in figure 2 is used to explain the model details. The river reaches, $r_{e}$, along the river are defined in such a way that the physical and hydraulic properties (such as flow depth, discharge and channel roughness) within a reach remain unchanged. The confluence of a tributary, presence of a point source of pollution or a marked change in the river cross-section typically defines a new reach. The river system consists of a set of dischargers, $d$, that are allowed to release the pollutants into the river after removing some 


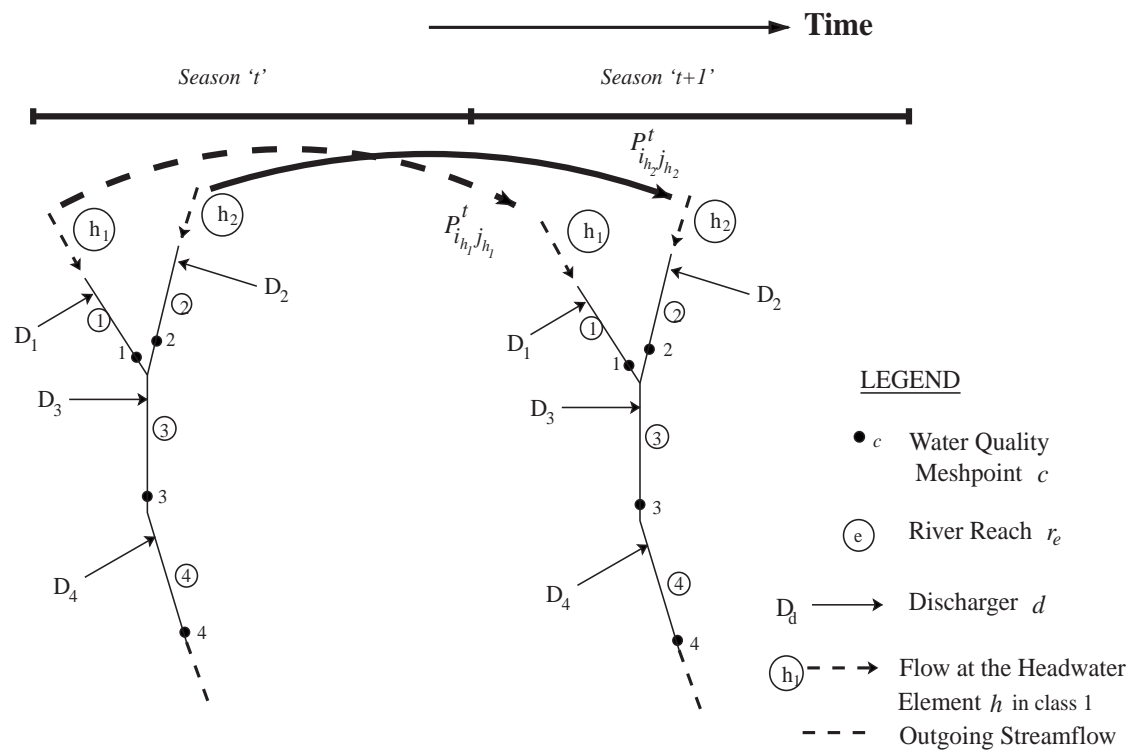

Figure 2. A general river system used in the model.

fraction of the pollutants. These fraction-removal levels are necessary to maintain acceptable water quality condition in the river as prescribed by the pollution control agency. A common practice of the pollution control agency to ensure an acceptable water quality condition is to check the water quality at a finite number of locations in the river, called the checkpoints (mesh points). The water quality at a checkpoint, $c$, is described by means of some indicators called the water quality indicators. The dissolved oxygen deficit (DO deficit) is an example of a water quality indicator. The concentration level of a water quality indicator at a checkpoint is affected by controllable as well as uncontrollable sources of pollutants in the river system. The response of river system to these sources of pollution can be integrated into the SDP model using an appropriate water quality simulation model (such as the Streeter-Phelps model). The concentration level of a water quality indicator is expressed as a function of the fractionremoval levels which form the decision variables in the SDP model. In figure 2, the random variation of streamflows entering into the river system at the headwater elements, $h$, across seasons is represented by transition probabilities, $P_{i_{h} j_{h}}^{t}$.

\subsection{State variables}

In a hydrologic system, variables influencing a decision are of such a wide range that it becomes computationally impossible to include all of them as state variables in a SDP model, because of the 'curse of dimensionality' associated with dynamic programming. It is, therefore, necessary to choose only those variables that influence the decision process the most, to define the state of the system. Keeping this in view, the following are considered as state variables in the SDP model: (i) $\mathbf{K}$, the dissolved oxygen deficit (DO deficit) vector, representing the initial DO deficit at the beginning of reaches containing checkpoints at the beginning of the season $t$ and, (ii) I, the streamflow vector, representing streamflows at the headwaters during the season $t$. The vector $\mathbf{K}$ consists of initial DO deficits at the beginning of reaches containing checkpoints, and may be written as, $\mathbf{K}=\left\{k_{1}, k_{2}, \ldots, k_{N C}\right\}$, where $k_{c}$ is the initial 
DO deficit class interval at the beginning of the reach containing the checkpoint $c$ and NC is the number of checkpoints. There can be more than one checkpoint in each reach. In that case, the DO deficit vector $\mathbf{K}$ will have number of elements equal to number of checkpoints with equal values of $k_{c}$ for checkpoints belonging to the same reach. However, other influencing parameters such as the time of travel of streamflow from the beginning of the reach to different checkpoints in the same reach may vary. If a reach does not contain a checkpoint, that reach is not included in the state vector. Similarly, the vector I consists of streamflows at the headwaters during the season $t$, and may be written as, $\mathbf{I}=\left\{i_{1}, i_{2}, \ldots, i_{N H}\right\}$, where $i_{h}$ is the streamflow class interval at the headwater $h$ during the season $t$ and $\mathrm{NH}$ is the number of headwaters. As the number of headwaters and checkpoints increases, the model dimension also increases. To ensure computational tractability, therefore, the model application is limited to only upto about four or five check points and four or five head waters.

The state variables are discretised for use in the SDP model. Discretisation of a state variable is carried out by dividing the entire range of the variable into a number of class intervals, not necessarily of equal length. All values of the variable falling into a particular class are represented by a single value within the class which is taken to be the representative value of that class interval. As the number of class intervals increases for a state variable, a better approximation of the result would, in general, be achieved, but the computational requirements will also increase. On the other hand, a coarse discretisation of the state variables may result in trapping states (same states being successively visited many times). Therefore, a good criterion to choose the number of class intervals for the different state variables is to avoid trapping states in operation while ensuring computational tractability. This requires a trial and error approach before finalising the state discretisation scheme. In addition, discretisation of the decision variable (fraction-removal level) must be done in conjunction with the state variable discretisation to ensure that different feasible combinations of the state variable intervals lead to different decisions. It must also be noted that the effect of discretisation on the resulting decisions depend on the signifcance of the particular state variable in the water quality management process. For example, the head water discretisation may have a more significant impact on the optimal decisions compared to that of the DO deficit.

\subsection{Decision variable}

Since the river water quality is primarily influenced by the streamflows, which change significantly across seasons, fraction-removal decisions need to be specified for every stage (season). In the SDP waste load allocation model, seasonal fraction-removal levels are considered as decision variables. That is, $\mathbf{X}_{t}$, the effluent treatment vector, representing the fraction-removal levels for each discharger in the season $t$ is the decision vector. The vector $\mathbf{X}_{t}$ consists of seasonal fraction-removal levels for each discharger, and is written as, $\mathbf{X}_{t}=\left\{x_{1 t}, x_{2 t}, \ldots, x_{N D t}\right\}$, where $x_{d t}$ is the effluent treatment level class interval for the discharger $d$ in season $t$ and ND is the number of dischargers.

\subsection{Stochastic nature of streamflows}

Streamflow is the most important hydrologic variable influencing the waste load allocation decisions. It affects the downstream water quality to a significant extent. The streamflow in any season $t$ is not known with certainty in advance; only the probability distribution of the streamflow can be estimated. In the SDP formulation (Loucks et al 1981), it is assumed that the seasonal streamflows constitute a simple (or one-step) Markov process. The assumption of a one-step Markov process, which may not strictly be valid for all 
hydrologic variables, is nevertheless a good approximation that makes the computations significantly simpler than with assumption of higher order dependence. The conditional probability $P\left[Q_{j_{h} t+1}=j_{h} / Q_{i_{h} t}=i_{h}\right]$, that is the probability of streamflow in season $t+1$ being in state $j_{h}$ given that it is in state $i_{h}$ in season $t$, is the one-step transition probability and is denoted by $P_{i_{h} j_{h}}^{t}$. For a given class interval $i_{h}$, the streamflow in period $t+1$ should belong to one of the class intervals $j_{h}$, so that the sum of the transitional probabilities $P_{i_{h} j_{h}}^{t}$ over all possible values of $j_{h}$ should equal to unity.

Another important assumption made in the SDP models is that the streamflow series is a stationary stochastic process. This implies that the transition probability matrix does not change from year to year. This assumption assures a steady-state fraction-removal polic from the model.

\subsection{Development of the recursive equation}

Let $\lambda$ denote a measure of the system performance whose expected value must be optimised in the SDP model. $\lambda$ is a function of the initial DO deficit vector $\mathbf{K}$, streamflow vector $\mathbf{I}$, and the treatment vector (decision vector) $\mathbf{X}$ in season $t$. For given values of initial DO deficit vector $\mathbf{K}$, streamflow vector $\mathbf{I}$ and the treatment vector $\mathbf{X}$ and season $t, \lambda$ is evaluated using a fuzzy decision model.

$\lambda$ is the fuzzy decision corresponding to the goals of pollution control agencies and effluent discharging bodies. It is obtained for a given $\mathbf{K}, \mathbf{I}$ and $\mathbf{X}$ from the fuzzy decision model, discussed subsequently. It is interpreted as the level of satisfaction among conflicting objectives, and thus, a higher value of $\lambda$ would be desirable (see for a detailed discussion, Kindler 1992, and Mujumdar \& Sasikumar 2002). The objective function of the stochastic dynamic programming model is written as

$$
\begin{aligned}
& \text { maximise } E[\lambda(\mathbf{K}, \mathbf{I}, \mathbf{X}, t)] \quad \forall \quad \mathbf{K}, \mathbf{I} \\
& \{\text { feasible } \mathbf{X}\}
\end{aligned}
$$

where $E$ is the expectation operator. For convenience in writing, $\lambda(\mathbf{K}, \mathbf{I}, \mathbf{X}, t)$ is written as $\lambda_{t}$.

Following Loucks et al (1981), a backward recursive relationship is developed, starting with the last season in some arbitrary year $S$ in future. Let NP be the number of periods (seasons) remaining till the end of the year $S$, and $f_{t}^{N P}(\mathbf{K}, \mathbf{I})$ represent the total expected value of the system performance measure with $N P$ periods to go, including the current period $t$, given that the initial DO deficit vector is $\mathbf{K}$ at the beginning of the season $t$ and streamflow vector is $\mathbf{I}$ during the season $t$.

In order to formulate the general recursive relationship for the SDP model, consider two adjacent time periods, $t$ and $t+1$. For known values of $\mathbf{K}$ and $\mathbf{I}$ in period $t$, the system performance $\lambda_{t}$ is determined from the fuzzy decision model, for the particular decision vector $\mathbf{X}$ being examined in the optimization. The expected value of the system performance for the subsequent period $t+1$, is determined from the state transformations: $\mathbf{K}$ to $\mathbf{L}$, which is determined by the water quality simulation model and, $\mathbf{I}$ to $\mathbf{J}$, which is random and governed by streamflow transition probabilities. Since $\mathbf{I}$ and $\mathbf{J}$ represent streamflows at the headwaters in seasons $t$ and $t+1$ respectively, the transition from $\mathbf{I}$ to $\mathbf{J}$ is to be interpreted as follows: $\mathbf{I}$ represents streamflows at each of the headwaters in season $t$. For a headwater $h$, the streamflow transits from a state $i_{h}$ in season $t$ to state $j_{h}$ in season $t+1$ randomly. The probability of transition from a state $i_{h}$ in season $t$ to state $j_{h}$ in season $t+1$ is given by streamflow transition probability, $P_{i_{h} j_{h}}^{t}$. It is assumed that the streamflows at a headwater is stochastically independent of streamflow at other headwaters. This assumption is valid only when 
the streamflows entering the headwaters in the river stretch under study, are generated from hydrologically different regions. The independence assumption can be verified from the historical streamflow data at the headwaters. When the independence assumption is not valid, then joint probabilities have to be used in the recursive relationship, which renders the model extremely complex. Assuming that the seasonal transitions of streamflows at the headwaters are independent of each other, the product of seasonal transition probabilities of all the headwaters is used in the recursive relationship to obtain the transition from vector $\mathbf{I}$ to vector $\mathbf{J}$. The general recursive relationship for a season $t$ corresponding to the stage NP is written as,

$$
f_{t}^{N P}(\mathbf{K}, \mathbf{I})=\underset{\{\text { feasible } \mathbf{X}\}}{\operatorname{Max}}\left[\lambda_{t}+\sum_{\mathbf{J}} \prod_{h=1}^{N H} P_{i_{h} j_{h}}^{t} f_{t+1}^{N P-1}(\mathbf{L}, \mathbf{J})\right] \forall \quad \mathbf{K}, \mathbf{I} .
$$

In (2), the summation over vector $\mathbf{J}$ should be interpreted as follows: the streamflow state during the season $t, i_{h}$ at headwater $h$ transits to a state $j_{h}$ in season $t+1$ with a probability, $P_{i_{h} j_{h}}^{t}$. Once the new state of streamflows $\left(j_{h}\right)$ at all headwaters is known in season $t+1$, vector $\mathbf{J}$ is defined. The summation is carried over all possible values of $\mathbf{J}$ to get the expected value of the system performance over the remaining periods. In (2), $t$ is reckoned to be $1,2, \ldots, T$ in the forward direction and NP which denotes the stage number, $1,2, \ldots$ is reckoned backwards from the last period. Use of both indices facilitates tracing of the stage by stage movement of the DP algorithm.

Starting at some period in the future and using the seasonal transition probabilities of the streamflow, it is possible to arrive at values of vector $\mathbf{L}$ for each time period $t$ as a function of the state variables DO deficit vector, $\mathbf{K}$ and streamflow vector, $\mathbf{I}$. When the recursive equations are solved for each period in successive years, the policy $\mathbf{X}^{*}(\mathbf{K}, \mathbf{I}, t)$ will relatively quickly repeat itself in each successive year for all periods $t$. The steady-state policy is said to have reached, when this occurs for all periods $t$, implying that the expected annual performance $\left[f_{t}^{N P+T}(\mathbf{K}, \mathbf{I})-f_{t}^{N P}(\mathbf{K}, \mathbf{I})\right]$ is constant for all states $\mathbf{K}, \mathbf{I}$ and all periods $t$ within a year. This steady-state condition is ensured because the performance measure $\lambda_{t}$ and the inflow transition probabilities $P_{i_{h} j_{h}}^{t}$ do not change from year to year.

The optimal treatment vector, $\mathbf{X}_{\mathbf{t}}{ }^{*}=\left\{x_{1 t}^{*}, x_{2 t}^{*}, \ldots, x_{N D t}^{*}\right\}$, is thus obtained for a given initial DO deficit vector $\mathbf{K}=\left\{k_{1}, k_{2}, \ldots, k_{N C}\right\}$ and streamflow vector $\mathbf{I}=\left\{i_{1}, i_{2}, \ldots, i_{N H}\right\}$ for each period $t$, by solving the stochastic dynamic programming formulation. The following section discusses the fuzzy decision model which is used to compute the system performance measure $\lambda$.

\section{Fuzzy decision model}

The fuzzy decision model (FDM) used in this study is adapted from Sasikumar \& Mujumdar (1998). This section describes the salient features of the model, as adapted for the problem addressed. The system performance measure required for the SDP model is expressed in terms of the goals of pollution control agency and effluent discharging bodies. The fuzzy decision model evaluates the system performance measure for a given state of the system. For a known intial state of the system defined by beginning-of-season DO deficit vector, $\mathbf{K}$ and streamflow vector, $\mathbf{I}$, a suitable water quality model gives the end-of-season DO deficit vector $\mathbf{L}$ for a specified treatment vector $\mathbf{X}$. Since the goals of pollution control agency and dischargers are expressed in terms of DO deficit vector $\mathbf{L}$ and treatment vector $\mathbf{X}$, the response of the pollution control agency and dischargers to each element of $\mathbf{L}$ and $\mathbf{X}$ is considered a 
fuzzy set and appropriate membership grades are assigned to each of such fuzzy sets. The FDM evaluates the fuzzy decision corresponding to the fuzzy goals and constraints to give the system performance measure required for the SDP model. The next subsection discusses the fuzzy goals for water quality management.

\subsection{Membership functions for the fuzzy goals}

The only pollutant considered in the system is the BOD waste load released from the dischargers. The water quality indicator of interest is the DO deficit at a finite number of checkpoints, due to these point sources. The value of the DO deficit at a checkpoint can be expressed in terms of fraction-removal levels of BOD associated with various dischargers located upstream of the checkpoint. The transfer function that expresses the DO deficit at a checkpoint in terms of concentration of point-source of BOD and the fraction-removal levels are obtained using the one dimensional steady-state Camp-Dobbins modifications to the Streeter-Phelps (1925) BOD-DO equations.

The response of the pollution control agency and the dischargers to each element of the DO deficit vector, $\mathbf{K}$, and the treatment vector, $\mathbf{X}$ is treated as a fuzzy set with an appropriate membership function. The response of the water quality in the river system, in terms of DO deficit (i.e., $\mathbf{L}$ ), as a result of the treatment $\mathbf{X}$ applied for known $\mathbf{K}$ and $\mathbf{I}$ is determined from the water quality simulation model. In the SDP model, search is made for the particular treatment vector $\mathbf{X}$ in period $t$ which miximizes the expected value of the system performance measure, $\lambda$ for given $\mathbf{K}$ and $\mathbf{I}$. The fuzzy response of the pollution control agencies and dischargers to the resulting DO deficit vector, $\mathbf{L}$ and the decision vector $\mathbf{X}$ is used appropriately to compute the system performance measure $\lambda$, using the fuzzy decision model, defined as,

$$
\lambda(\mathbf{K}, \mathbf{I}, \mathbf{X}, t)=\operatorname{minimum}\left[\mu_{\mathbf{E}_{c}}\left(l_{c}\right) \bigcap \mu_{\mathbf{F}_{d}}\left(x_{d}\right)\right],
$$

where $\mu_{\mathbf{E}_{\mathfrak{c}}}\left(l_{c}\right)$ is the fuzzy membership grade of the response of the pollution control agency to end-of-season DO deficit class interval $l_{c}$ at the checkpoint $c$ and $\mu_{\mathbf{F}_{d}}\left(x_{d}\right)$ is the fuzzy membership grade of the response of discharger $d$ to the effluent treatment class interval $x_{d}$. $\mathbf{E}_{c}$ and $\mathbf{F}_{d}$ are the goals of PCA and dischargers with respect to water quality at check point $c$ and fraction-removal level at discharger $d$ respectively, and are expressed as fuzzy sets. Equation (3) is a mathematical statement of the definition of fuzzy decision (Bellman \& Zadeh 1970), which states that the fuzzy decision of a set of goals and constraints is the intersection of the corresponding fuzzy sets. Intersection of fuzzy sets is given by the minimum among all the membership functions of the fuzzy sets. $\lambda$ is interpreted as the minimum goal satisfaction in the system, and its expected value is maximized in the SDP. $\lambda(\mathbf{K}, \mathbf{I}, \mathbf{X}, t)$ as obtained from (3) is used in the SDP recursive equation (2).

The membership functions of the fuzzy sets are subjective statements of the perceptions of the decision makers. For example, the membership function for the DO deficit indicates the decision maker's perception of the degree of low quality, to a given DO deficit. The lower and upper bounds of the membership functions are also subjective, and in general depend on the particular problem being solved. To address such uncertainty in the lower and upper bounds of the membership functions the fuzzy membership functions themselves may be treated as fuzzy in the model and may be modelled using interval gray numbers. This, however, is not done in the paper. It may be noted that allowing the lower limits of the fuzzy membership functions to be less than the normally used standard values such as $5 \mathrm{mg} / \mathrm{L}$ for DO, and shaping the membership functions with respect to biological information on DO requirements for aquatic life, for example, would be a useful application of the methodology presented in the paper. 


\subsection{Solution of the recursive equation}

With all the values required for the recursive equation ready, (2) is solved repeatedly, starting with NP $=1$ when $t=T$, till a steady-state policy is reached. For each feasible combination of $\mathbf{K}, \mathbf{I}$ and $\mathbf{X}$, a value of $\lambda_{t}$ and an associated vector of $\mathbf{L}$ for a given time period $t$ is obtained from the fuzzy decision model to evaluate the recursive function $f_{t}^{N P}(\mathbf{K}, \mathbf{I})$.

The iterations are continued till the optimal policy $\mathbf{X}^{*}(\mathbf{K}, \mathbf{I})$ attains a steady-state for all $t$ in a year. This occurs when the expected annual performance $\left[f_{t}^{N P+T}(\mathbf{K}, \mathbf{I})-f_{t}^{N P}(\mathbf{K}, \mathbf{I})\right]$ becomes constant for all values of $\mathbf{K}$ and $\mathbf{I}$ for all $t$. The final values $\mathbf{X}(\mathbf{K}, \mathbf{I})$ for each time period $t$ define the optimal operating policy and are denoted by $\mathbf{X}^{*}(\mathbf{K}, \mathbf{I}, t)$.

\section{Application to a case study}

The model is applied to a stretch of the Tungabhadra river system in South India, shown in figure 3. Tungabhadra is a perennial river formed by the confluence of the rivers Tunga and Bhadra. Downstream of the Bhadra Headwaters (Lakavalli), industries are located along the bank of the river. Similarly, towns are located downstream of the Tunga river. Downstream of the junction of the Tunga and Bhadra rivers, both industries and towns are located along the west bank of the river. The river receives the waste loads from four major effluent points which include two industrial and two municipal bodies. The model is applied to a river stretch of $131 \mathrm{~km}$ that comprises the two head waters (Tunga and Bhadra) and four point loads (two industrial and two municipal effluent loads). To keep the application simple to demonstrate major features of the model, incremental flow and withdrawal along the streams are neglected. The water enters the system, therefore, in the form of only fresh water flows through the head waters or effluent flows through the point loads.

The river is discretised into a number of reaches which are defined such that model input parameters or coefficients (physical, chemical, and biological of type) remain constant within a reach. Whenever a new junction is encountered or a significant change in the model input coefficients occurs, a new reach is defined from that location. Accordingly, the $131 \mathrm{~km}$ long stretch of the river is divided into nine reaches of varying lengths.

All the four dischargers discharge BOD effluents to the river. The water quality indicator of interest is DO deficit at four checkpoints due to these point sources of BOD, as shown in

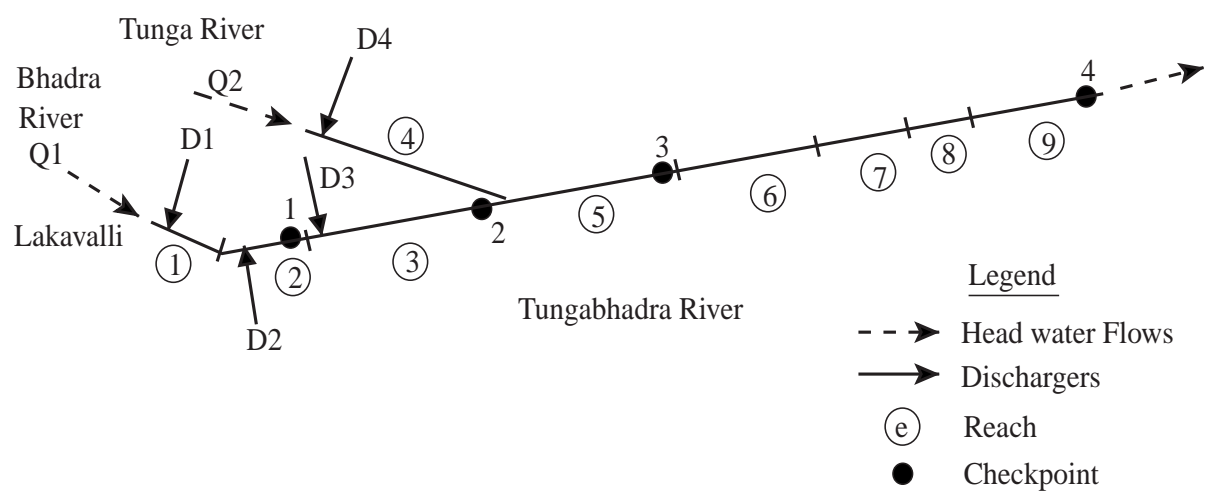

Figure 3. Schematic diagram of the river system. 
Table 1. Relevant data of river reaches.

\begin{tabular}{|c|c|c|c|c|c|c|}
\hline \multirow[b]{2}{*}{$\begin{array}{l}\text { Reach } \\
\text { no. }\end{array}$} & \multirow[b]{2}{*}{$\begin{array}{l}\text { Width } \\
\text { (m) }\end{array}$} & \multirow{2}{*}{$\begin{array}{l}\text { Length } \\
(\mathrm{km})\end{array}$} & \multirow[b]{2}{*}{$\begin{array}{c}\text { Manning's } \\
\text { coeff. }\end{array}$} & \multirow[b]{2}{*}{$\begin{array}{l}\text { Longitudinal } \\
\text { slope }\end{array}$} & \multicolumn{2}{|c|}{ Temperature $\left({ }^{\circ} \mathrm{C}\right)$} \\
\hline & & & & & Mean & Std. dev.* \\
\hline 1 & $200 \cdot 00$ & 4 & 0.0500 & 0.000035 & $26 \cdot 91$ & $1 \cdot 85$ \\
\hline 2 & $143 \cdot 12$ & 3 & 0.0440 & 0.000076 & $25 \cdot 90$ & $2 \cdot 21$ \\
\hline 3 & $75 \cdot 00$ & 20 & $0 \cdot 0800$ & $0 \cdot 000050$ & $25 \cdot 97$ & $2 \cdot 21$ \\
\hline 4 & $216 \cdot 22$ & 20 & 0.0160 & $0 \cdot 000025$ & $26 \cdot 77$ & $2 \cdot 04$ \\
\hline 5 & $250 \cdot 00$ & 20 & $0 \cdot 0400$ & 0.000190 & 27.77 & 1.93 \\
\hline 6 & $250 \cdot 00$ & 20 & $0 \cdot 0400$ & $0 \cdot 000190$ & $27 \cdot 77$ & 1.93 \\
\hline 7 & $245 \cdot 00$ & 10 & 0.0655 & $0 \cdot 000054$ & 27.77 & 1.93 \\
\hline 8 & $215 \cdot 12$ & 14 & $0 \cdot 0700$ & 0.000600 & 27.77 & 1.93 \\
\hline 9 & $215 \cdot 12$ & 20 & $0 \cdot 0700$ & $0 \cdot 000600$ & 27.77 & 1.93 \\
\hline
\end{tabular}

*Std. dev.: Standard deviation

figure 3. At most one checkpoint is considered in a reach in order to reduce the computational effort. The data required for the simulation model is collected from government sources (e.g., Karnataka State Pollution Control Board, Water Resources Development Organisation) and a few industries. This data includes: (i) details of discharges, and DO, BOD concentrations of both head water and effluent flows; (ii) details of river geometry, and (iii) temperature details of the waste load and the river flow. Table 1 gives the data pertaining to the geometrical details, Manning's roughness coefficient and initial values of temperature for various reaches. A geometrical cross-section of rectangular shape is considered for the river. The four checkpoints are located at the end of reaches 2, 3,5 and 9. These checkpoints are chosen based on their critical locations in the river for water quality considerations. Mean time of travel of the flow from the beginning of a reach to a checkpoint, if present in that reach, or to the end point of the reach if there is no checkpoint in the reach, is given in table 2. Effluent flow data is provided in table 3. Effluent flow data is considered to be constant across seasons.

Table 2. Time of travel from beginning of a reach to a checkpoint / end of the reach.

\begin{tabular}{lcc}
\hline & \multicolumn{2}{c}{ Time of travel } \\
\cline { 2 - 3 } $\begin{array}{l}\text { Reach } \\
\text { no. }\end{array}$ & $\begin{array}{c}\text { Checkpoint } \\
\text { (day) }\end{array}$ & $\begin{array}{c}\text { End point } \\
\text { (day) }\end{array}$ \\
\hline 1 & - & 0.323 \\
2 & $0 \cdot 123$ & 0.123 \\
3 & $1 \cdot 343$ & 1.343 \\
4 & - & 0.572 \\
5 & 1.483 & 1.483 \\
6 & - & 0.951 \\
7 & - & 0.376 \\
8 & - & 0.039 \\
9 & 0.281 & 0.281 \\
\hline
\end{tabular}




\subsection{Discretisation of state and decision variables}

The state variables in the SDP model are beginning-of-season DO deficit at the four checkpoints and streamflow during the season at the two headwaters. The state vector thus consists of six variables. For use in the SDP model, these variables are discretised into a number of class intervals. Details of discretisation of these state variables are presented in the following subsections.

5.1a Discretisation of headwater flow: For each headwater, seasonal average discharge is used to compute the transition probabilities. The seasonal average discharge at each headwater is first discretised into four class intervals for each season. Table 4 gives the discretisation of seasonal average discharge at the two headwaters for the three seasons. Since there are two headwaters and four classes for each headwater flow, total number of streamflow states of both headwaters together, is 16 . Seasonal transitional probabilities of streamflows at the two headwaters are computed using relative frequency approach. The seasonal transition probabilities for both headwaters are presented in table 5 .

5.1b Discretisation of DO deficit: The possible range of DO deficit at each checkpoint is divided into a number of class intervals. Each such class is represented by its representative value, usually the midpoint of the class interval. The minimum value of DO deficit at each checkpoint in all seasons is taken as zero and the maximum permissible DO deficit as $6.0 \mathrm{mg} / \mathrm{L}$. This range, 0-6, is divided into six equal classes, defined to be the same for all checkpoints in all the three seasons. Since DO deficit at each checkpoint can be in one of the six classes and there are four checkpoints, total number of elements in vector $\mathbf{K}$ will be $6^{4}=1296$. The total number of combinations of state variables (DO deficit and streamflow) is thus, $1296 \times 16=20736$. For each such combination of state variables, optimal decision vector (vector of fraction-removal levels, $\mathbf{X}$ ) is obtained from SDP model.

5.1c Discretisation of fraction-removal levels: The decision variable, $\mathbf{X}$, which is the vector of fraction-removal levels at the four dischargers is also discretised into a number of classes. A minimum fraction-removal level of $30 \%$ and a maximum fraction-removal level of $90 \%$ are assumed for the dischargers. Nine equal discrete states of fraction-removal levels are considered within this range. Table 6 gives the discrete state values of fraction-removal level considered for all dischargers in all seasons.

Table 3. Effluent flow data.

\begin{tabular}{|c|c|c|c|c|c|c|}
\hline \multirow[b]{2}{*}{$\begin{array}{l}\text { Discharger } \\
\text { no. }\end{array}$} & \multirow[b]{2}{*}{$\begin{array}{l}\text { Location } \\
\text { (reach no.) }\end{array}$} & \multirow{2}{*}{$\begin{array}{c}\text { BOD } \\
\text { conc. } \\
(\mathrm{mg} / \mathrm{L})\end{array}$} & \multirow{2}{*}{$\begin{array}{c}\text { DO } \\
\text { conc. } \\
(\mathrm{mg} / \mathrm{L})\end{array}$} & \multicolumn{3}{|c|}{ Effluent flow data } \\
\hline & & & & $\begin{array}{l}\text { Mean } \\
\left(\mathrm{m}^{3} / \mathrm{s}\right)\end{array}$ & $\begin{array}{l}\text { Std. dev. } \\
\left(\mathrm{m}^{3} / \mathrm{s}\right)\end{array}$ & $\begin{array}{l}\text { Value used } \\
\qquad\left(\mathrm{m}^{3} / \mathrm{s}\right)\end{array}$ \\
\hline 1 & 1 & 1000 & $2 \cdot 0$ & 0.705 & $0 \cdot 154$ & 0.727 \\
\hline 2 & 2 & 440 & $2 \cdot 0$ & $0 \cdot 308$ & 0.077 & $0 \cdot 318$ \\
\hline 3 & 3 & 300 & $2 \cdot 0$ & $0 \cdot 026$ & $0 \cdot 002$ & $0 \cdot 027$ \\
\hline 4 & 4 & 900 & $2 \cdot 0$ & 0.436 & $0 \cdot 109$ & 0.450 \\
\hline
\end{tabular}

Note: No. $=$ number; conc. $=$ concentration; std. dev. $=$ standard deviation 


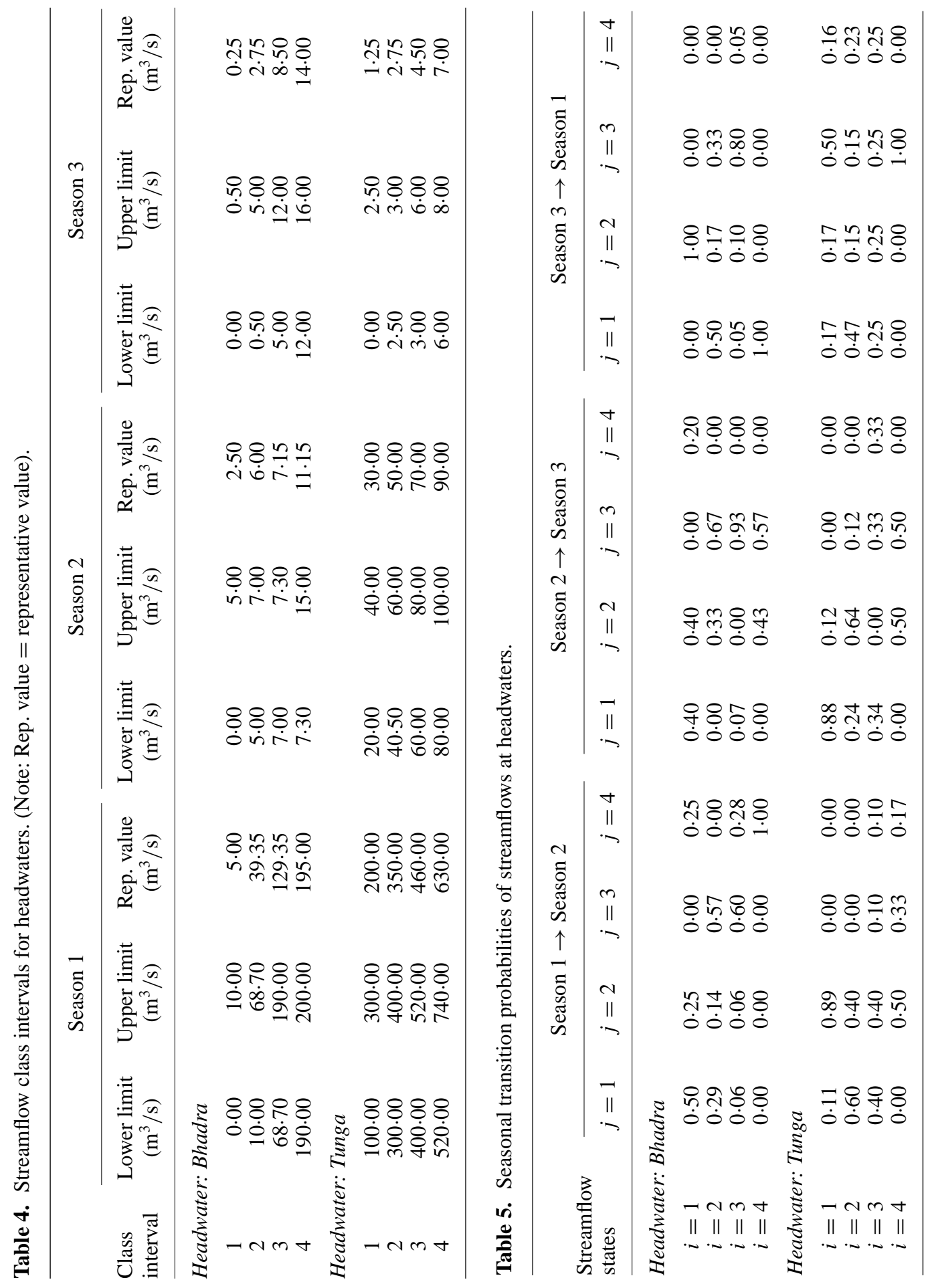


Table 6. Discrete states of fraction-removal levels.

\begin{tabular}{lccccccccc}
\hline Class & 1 & 2 & 3 & 4 & 5 & 6 & 7 & 8 & 9 \\
\hline Rep. value & 0.30 & 0.38 & 0.45 & 0.53 & 0.60 & 0.68 & 0.75 & 0.83 & 0.90 \\
\hline
\end{tabular}

Since the value of fraction-removal level for each discharger can be one among the nine discrete states, and there are four dischargers, total number of elements in the decision vector $\mathbf{X}$ is $9^{4}=6561$. For each combination of state variables, a search is therefore made over 6561 possible values of decision vector $\mathbf{X}$ to arrive at the optimal decision vector in the SDP model. It is to be noted that the water quality simulation and the fuzzy decision models are invoked $1296 \times 16 \times 6561$ times to get the response of the system in terms of DO deficit vector $\mathbf{L}$ and the system performance measure for each stage. This is repeated for all stages until the steady-state condition is achieved. It thus involves a very large computational effort. On a high-speed IBM workstation, the CPU time required for achieving the steady-state policy was around four hours. It must however be noted that this is a one-time requirement, and once the policy is derived, implementation of the policy requires negligible computational effort.

The recursive method proposed by Fugiwara et al (1986) is used with minor modifications, for modelling the BOD-DO transport in the river. The method is referred to in this paper as the influence coefficient recursive method (ICRM). Table 7 gives the coefficients required to compute the resulting DO deficit at a checkpoint for $K=\{1,1,1,1\}$ and $I=\{4,4\}$ in all

Table 7. ICRM coefficients for $K=\{1,1,1,1\}$ and $I=\{4,4\}$.

\begin{tabular}{lccccc}
\hline & & \multicolumn{4}{c}{$(-1) \times$ Coefficient of } \\
\cline { 3 - 6 } $\begin{array}{l}\text { Checkpoint } \\
\text { no. }\end{array}$ & $\begin{array}{c}\text { Constant } \\
\text { term }\end{array}$ & $x_{1}$ & $x_{2}$ & $x_{3}$ & $x_{4}$ \\
\hline Season 1 & & & & & \\
& & & & & 0.0000 \\
1 & 1.1073 & 0.2799 & 0.0169 & 0.0000 & 0.0000 \\
2 & 1.9617 & 0.8242 & 0.1578 & 0.0086 & 0.0000 \\
3 & 0.3512 & 0.0802 & 0.0161 & 0.0007 & 0.0421 \\
4 & 0.1972 & 0.0701 & 0.0143 & 0.0008 & 0.0501
\end{tabular}

Season 2

$\begin{array}{lrrrrr}1 & 6.9275 & 5.9575 & 0.6655 & 0.0000 & 0.0000 \\ 2 & 13.4338 & 10.6289 & 2.5346 & 0.1537 & 0.0000 \\ 3 & 0.2848 & 0.0888 & 0.0217 & 0.0013 & 0.1725 \\ 4 & 0.2676 & 0.0832 & 0.0203 & 0.0013 & 0.1627\end{array}$

Season 3

\begin{tabular}{rrrrrr}
1 & 5.5284 & 4.7035 & 0.4510 & 0.0000 & 0.0000 \\
2 & $12 \cdot 1431$ & 9.6511 & 2.1765 & 0.1286 & 0.0000 \\
3 & 0.5162 & 0.1893 & 0.0439 & 0.0027 & 0.2802 \\
4 & 0.3018 & 0.1107 & 0.0257 & 0.0016 & 0.1638 \\
\hline
\end{tabular}


seasons. A sample of the ICRM coefficients to obtain the DO deficit vector, $\mathbf{L}$, in terms of the fraction-removal levels, $\mathbf{X}$, for a known $\mathbf{K}$ and $\mathbf{I}$ is given in table 7 . As an illustration, for $K=\{1,1,1,1\}$ and $I=\{4,4\}$, the DO deficit at the checkpoint 2 in season 1 is calculated as:

$$
1.9617-0.8242 x_{1}-0.1578 x_{2}-0.0086 x_{3}-0 x_{4} .
$$

\subsection{Model solution}

The goals of the pollution control agencies and the dischargers are considered fuzzy sets. For the sake of simplicity, linear membership functions are defined for the fuzzy sets. The desirable concentration level and maximum permissible concentration level of the DO deficit at the checkpoints are presented in table 8. The aspiration levels and the maximum acceptable fraction-removal levels for the dischargers are presented in table 9. These parameters define the linear membership functions. As an illustration, membership function for response of PCA to end-of-season DO deficit at checkpoint 1 in season 2 is shown in figure 4. Similarly, membership function for the response of discharger 1 to fraction-removal level in season 2 is shown in figure 5. FDM calculates the system performance measure $\lambda(\mathbf{K}, \mathbf{I}, \mathbf{X}, t)$ for each possible input state. Table 10 gives a sample output of FDM for a resulting vector, $\mathbf{L}$ for some combinations of $\mathbf{K}$ and $\mathbf{I}$ when minimum fraction-removals are applied (i.e., $\mathbf{X}=\{1,1,1,1\}$ ), in season 1.

The values obtained from the fuzzy decision model, $\lambda(\mathbf{K}, \mathbf{I}, \mathbf{X}, t)$ are used in the recursive equation (2) to arrive at the steady-state fraction-removal policy. The steady-state policy is obtained after three annual cycles. It gives the values of optimal fraction-removal levels for

Table 8. Membership function parameters for goals of PCA.

\begin{tabular}{ccc}
\hline Checkpoint & $\begin{array}{c}\text { Desirable level }\left(A_{w c}^{D}\right) \\
(\mathrm{mg} / \mathrm{L})\end{array}$ & $\begin{array}{c}\text { Max. permissible level }\left(A_{w c}^{H}\right) \\
(\mathrm{mg} / \mathrm{L})\end{array}$ \\
\hline
\end{tabular}

Season 1

$\begin{array}{lll}1 & 0 \cdot 0 & 5 \cdot 5 \\ 2 & 0 \cdot 3 & 5 \cdot 7 \\ 3 & 0 \cdot 2 & 5 \cdot 4 \\ 4 & 0.5 & 5 \cdot 8\end{array}$

Season 2

$\begin{array}{lll}1 & 0 \cdot 5 & 5 \cdot 5 \\ 2 & 0 \cdot 4 & 5 \cdot 7 \\ 3 & 0 \cdot 6 & 5 \cdot 4 \\ 4 & 0 \cdot 3 & 5 \cdot 8\end{array}$

Season 3

\begin{tabular}{lll}
1 & $0 \cdot 6$ & $5 \cdot 8$ \\
2 & 0.7 & 5.9 \\
3 & 0.5 & $6 \cdot 0$ \\
4 & 0.9 & $5 \cdot 7$ \\
\hline
\end{tabular}

Note: $w=$ water quality indicator, DO deficit; $c=$ checkpoint 
Table 9. Membership function parameters for goals of dischargers.

Discharger $\quad$ Aspiration level $\left(x_{w d n}^{A s}\right) \quad$ Max. permissible level $\left(x_{w d n}^{M}\right)$

Season 1

$\begin{array}{lll}1 & 0.30 & 0 \cdot 80 \\ 2 & 0.30 & 0 \cdot 85 \\ 3 & 0.35 & 0.90 \\ 4 & 0.33 & 0 \cdot 88\end{array}$

Season 2

$\begin{array}{lll}1 & 0 \cdot 30 & 0 \cdot 90 \\ 2 & 0 \cdot 35 & 0 \cdot 85 \\ 3 & 0 \cdot 40 & 0 \cdot 80 \\ 4 & 0 \cdot 30 & 0 \cdot 80\end{array}$

Season 3

$\begin{array}{lll}1 & 0 \cdot 35 & 0 \cdot 90 \\ 2 & 0 \cdot 40 & 0 \cdot 90 \\ 3 & 0 \cdot 38 & 0 \cdot 88 \\ 4 & 0 \cdot 30 & 0 \cdot 90\end{array}$

Note: $w=$ water quality indicator, $\mathrm{DO}$ deficit $n=$ pollutant, $\mathrm{BOD} ; d=$ discharger

a given $\mathbf{K}$ and $\mathbf{I}$ in each season. Table 11 gives a sample output from the SDP model and specifies optimal fraction-removal levels for all seasons for some $\mathbf{K}$ and $\mathbf{I}$.

In season 1, the fraction-removal levels are generally low due to high streamflows. The fraction-removal levels in season 3 (Summer) are quite high compared to season 1 (Monsoon), due to low streamflows in the Summer season. It must be noted, however, that significant information - pertaining to random variation in streamflow, initial state of the system and fuzzy goals of the management problem - is used in arriving at these fraction-removal levels, and thus, the implication of such a policy of fraction-removal levels is very difficult to assess based on these summary results. A comparison of the implications of these fraction-removal levels (in terms of total treatment cost, reliability of quality, resileince resulting from the policy and other performance indicators) must be studied separately.

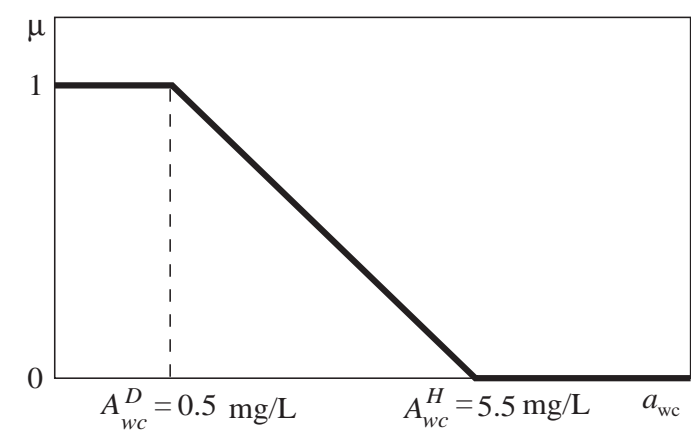

Figure 4. Membership function for goals of PCA w.r.t. DO deficit at checkpoint 1 in season 2. 


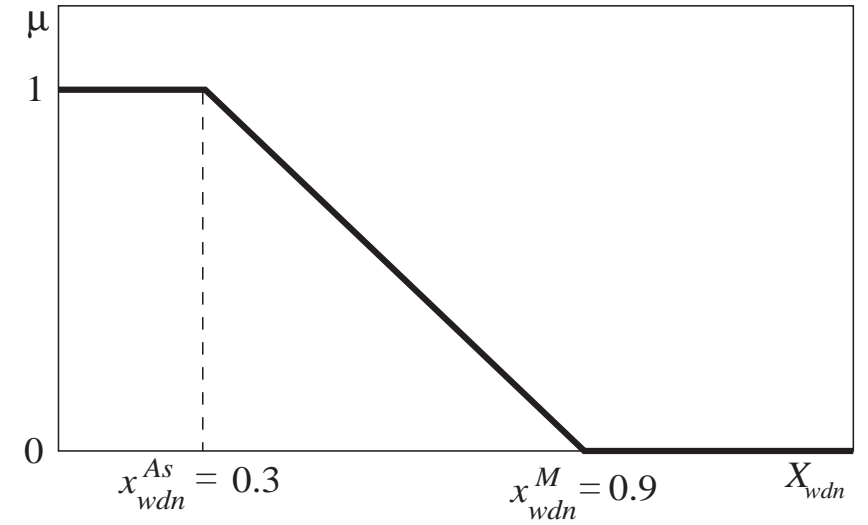

Figure 5. Membership function for goals of discharger 1 w.r.t. fraction removal level in season 2.

\section{Conclusion}

A stochastic dynamic programming model is developed to obtain a steady-state optimal fraction-removal policy which specifies the optimal fraction-removal levels in a season for given values of initial DO deficit vector and streamflow vector in season $t$. Initial DO deficit at the beginning of reaches containing the checkpoints and streamflows at the headwaters are the state variables in the SDP model. Streamflows at the headwaters are treated as random variables, and their transitions from one season to the next are modelled using seasonal transition probabilities. The procedure presented in the paper for arriving at a seasonal fractionremoval policy, includes a fuzzy decision model as a means of addressing uncertainty due to imprecision and subjectivity in specifying water quality and fraction-removal goals of the pollution control agencies and the dischargers. These goals are treated as fuzzy and are modelled with appropriate membership functions. Although for the case study, only linear membership functions are used, use of nonlinear membership functions poses no difficulty because the optimization algorithm (SDP) imposes no restrictions on linearity of the objective function.

Other sources of uncertainty (such as the model uncertainty in the water quality simulation model and random variations of variables other than streamflow)are not considered in the model, keeping computational tractability in view.

The model does not limit its application to any particular pollutant or water quality indicator of the river system. Appropriate water quality simulation model can be integrated with the SDP model to model the state transformation of the river system. For example the QUAL2E and the WASP6 models developed by the Environmental Protection Agency (EPA) may be integrated into the SDP model as transport models. However, in such cases the discretisation of the state variables plays a crucial role, as it may have a significant effect on the optimal decisions. Like all SDP models, the present model also suffers from limitations due to discretisation of the state and decision variables. The one-step Markov chain assumption for seasonal flows is generally valid in flows with pronounced annual cyclicity, and therefore use of the stochastic dynamic programming to derive seasonal fracion removal levels is justified in most cases. It is desirable to compare the results of policy implications with respect to other policies in practice, but this is not done in the present study, due to lack of adequate data on the case study. A limitation of the example problem presented in the paper is that non-point source of pollution is neglected because of lack of data. 


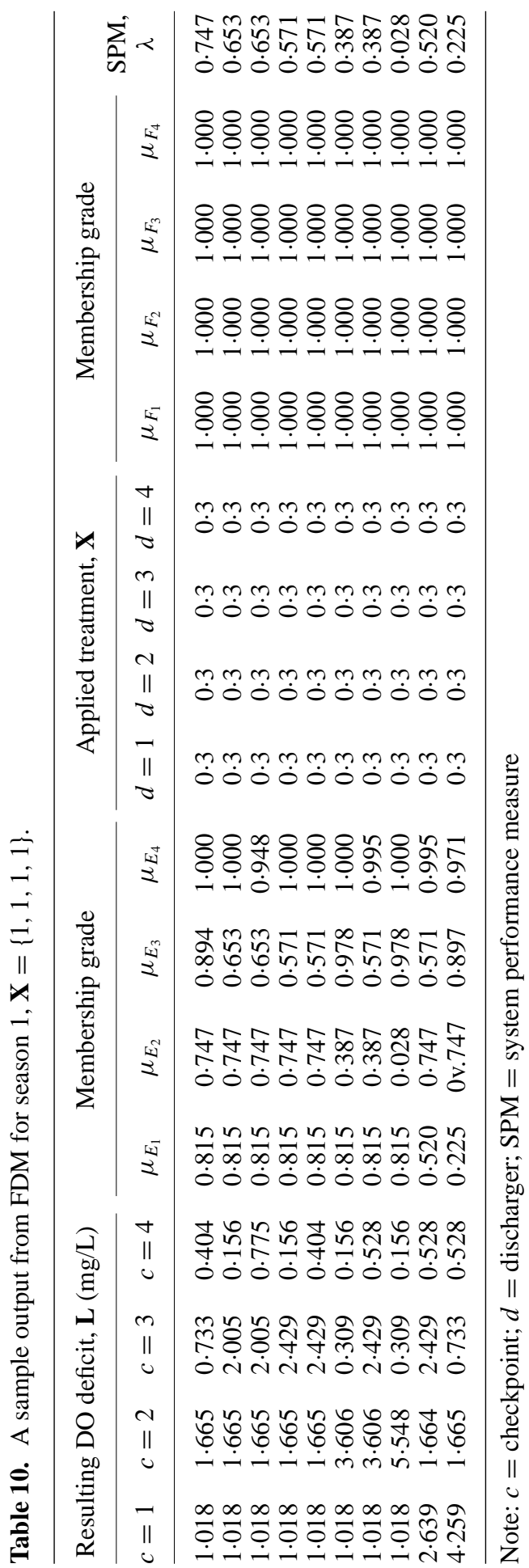


Table 11. Optimal fraction-removal policy (sample results).

\begin{tabular}{|c|c|c|c|c|c|c|c|c|c|c|}
\hline \multirow[b]{2}{*}{ Season } & \multicolumn{4}{|c|}{ Initial DO deficit vector, $\mathbf{K}$} & \multicolumn{2}{|c|}{ Streamflow vector, I } & \multicolumn{4}{|c|}{ Optimal treatment vector, $\mathbf{X}^{*}$} \\
\hline & $c=1$ & $c=2$ & $c=3$ & $c=4$ & $h=1$ & $h=2$ & $d=1$ & $d=2$ & $d=3$ & $d=4$ \\
\hline 1 & 1 & 1 & 1 & 1 & 4 & 4 & 2 & 2 & 3 & 3 \\
\hline 1 & 1 & 2 & 2 & 2 & 4 & 4 & 4 & 5 & 5 & 5 \\
\hline 1 & 2 & 1 & 1 & 1 & 4 & 4 & 4 & 4 & 5 & 4 \\
\hline 1 & 3 & 2 & 2 & 2 & 4 & 4 & 5 & 6 & 7 & 6 \\
\hline 2 & 1 & 1 & 1 & 1 & 4 & 4 & 7 & 7 & 6 & 6 \\
\hline 2 & 1 & 4 & 2 & 2 & 2 & 4 & 7 & 6 & 6 & 6 \\
\hline 2 & 1 & 6 & 1 & 4 & 3 & 2 & 8 & 7 & 7 & 6 \\
\hline 2 & 3 & 2 & 2 & 2 & 4 & 4 & 7 & 6 & 6 & 5 \\
\hline 3 & 1 & 2 & 2 & 2 & 4 & 4 & 6 & 7 & 6 & 6 \\
\hline 3 & 2 & 3 & 1 & 1 & 4 & 4 & 7 & 7 & 6 & 6 \\
\hline 3 & 3 & 1 & 1 & 1 & 3 & 4 & 8 & 8 & 7 & 7 \\
\hline 3 & 4 & 1 & 1 & 2 & 2 & 4 & 7 & 7 & 7 & 6 \\
\hline
\end{tabular}

Note: $c=$ checkpoint; $h=$ headwater; $d=$ discharger

\section{List of symbols}

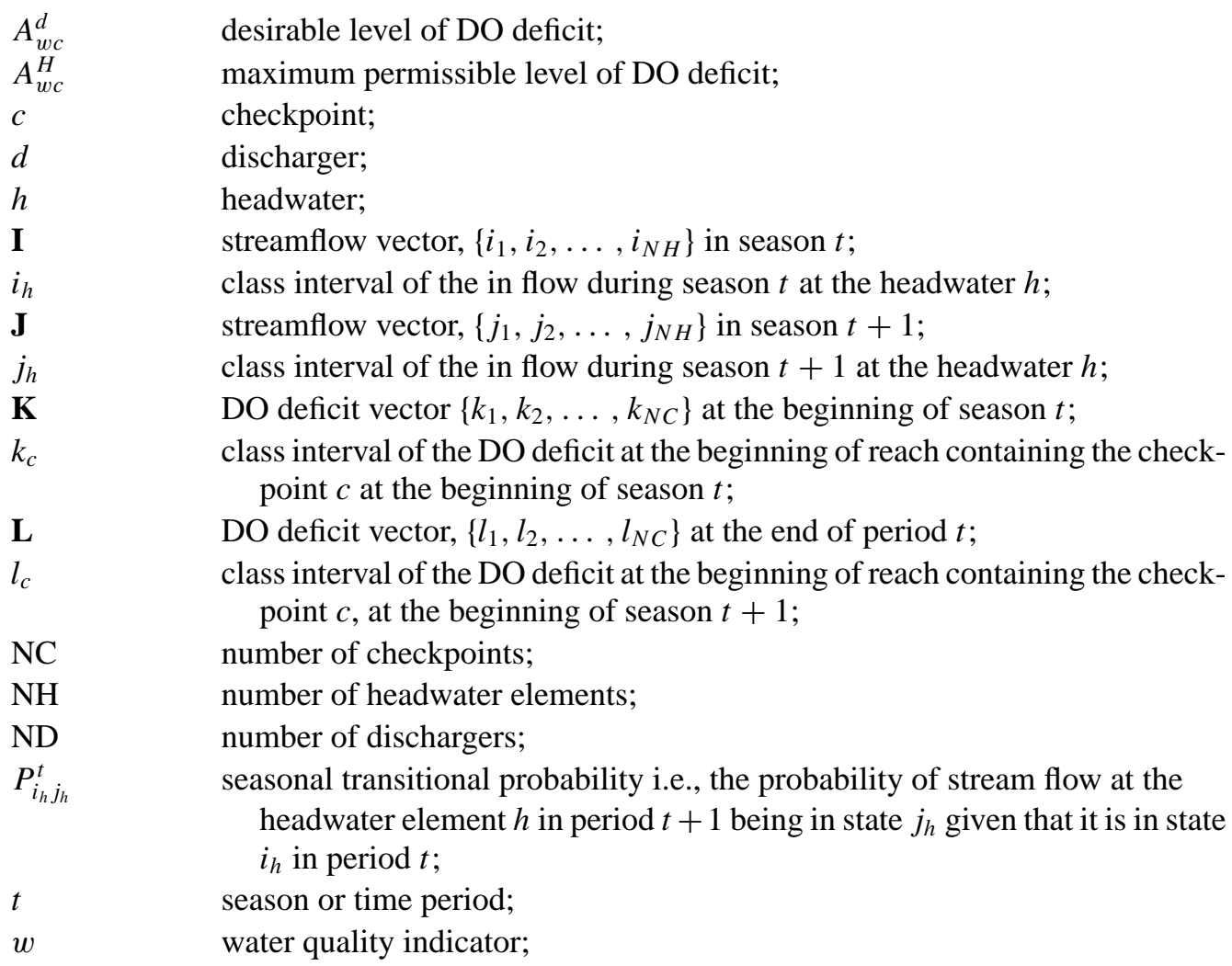




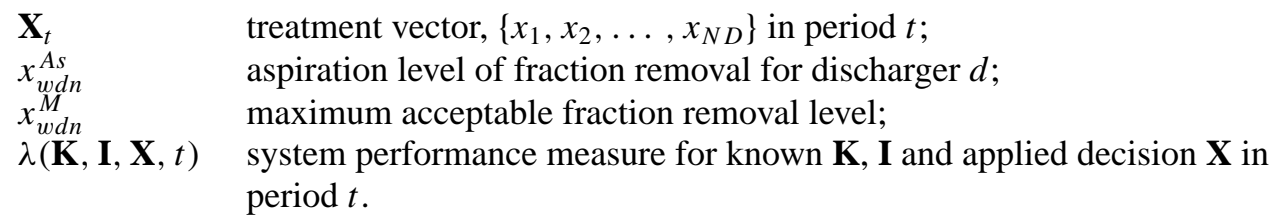

\section{References}

Bellman R E, Zadeh L A 1970 Decision-making in a fuzzy environment. Manage. Sci. B17: 141-164 Burn D H 1989 Water-quality management through combined simulation-optimization approach. $J$. Environ. Eng., ASCE 115: 1011-1024

Burn D H, Lence B J 1992 Comparison of optimization formulations for waste-load allocations. $J$. Environ. Eng., ASCE 118: 597-612

Burn D H, McBean E A 1985 Optimization modeling of water quality in an uncertain environment. Water Resources Res. 21: 934-940

Burn D H, McBean E A 1986 Linear stochastic optimization applied to biochemical oxygen demand - Dissolved oxygen modelling. Can. J. Environ. Eng. 13: 249-254

Carmichael J J, Strzepek K M 2000 A multiple-organic-pollutant simulation/optimization model of industrial and municipal wastewater loading to a riverine environment. Water Resources Res. 36: $1325-1332$

Dai T, Labadie J W 2001 River basin network model for integrated water quantity/quality management. J. Water Resources Planning Manage. 127: 295-305

Ellis J H 1987 Stochastic water quality optimization using embedded chance constraints. Water Resources Res. 23: 2227-2238

Fugiwara O, Gnanendran S K, Ohgaki S 1986 River quality management under stochastic stream flow. J. Environ. Eng., ASCE 112: 185-198

Fugiwara O, Gnanendran S K, Ohgaki S 1987 Chance constrained model for river water quality management. J. Environ. Eng., ASCE 113: 1018-1031

Kindler J 1992 Rationalizing water requirements with aid of fuzzy allocation model. J. Water Resources Planning Manage., ASCE 118: 308-323

Labadie J W 1997 Reservoir system optimization models. Water Resources Up-date, Universities Council on Water Resources 108: 83-110

Lence B J, Eheart J W 1990 Risk equivalent seasonal discharge programs for multidischargers streams. J. Water Resources Planning Manage., ASCE 116: 170-186

Lence B J, Takyi A K 1992 Data requirements for seasonal discharge programs: An application of a regionalized sensitivity analysis. Water Resources Res. 28: 1781-1789

Lohani B N, Thanh N C 1978 Stochastic programming model for water quality management in a river. J. Water Pollution Contr. Fed. 50: 2175-2182

Lohani B N, Thanh N C 1979 Probabilistic water quality control policies. J. Environ. Eng., ASCE 105: 713-725

Loucks D P, Lynn W R 1966 Probabilistic models for predicting stream quality. Water Resources Res. 2: 593-605

Loucks D P, Stedinger J R, Haith D A 1981 Water resources systems planning and analysis (Englewood Cliffs, NJ: Prentice Hall) 427-545

Mujumdar P P 2001 Uncertainty concepts in stream water quality management models. Research perspectives in hydraulics and water resources engineering (eds.) Rama Prasad, S Vedula (Singapore: World Scientific)

Mujumdar P P, Sasikumar K 2002 A fuzzy risk approach for seasonal water quality management of a river system. Water Resources Res. 38: 5-1-5-9

Rossman L A 1989 Risk equivalent seasonal waste load allocation. Water Resources Res. 25: 20832090 
Sasikumar K, Mujumdar P P 1998 Fuzzy optimization model for water quality management of a river system. J. Water Resources Planning Manage., ASCE 124: 79-88

Sasikumar K, Mujumdar P P 2000 Application of fuzzy probability in water quality management of a river system. Int. J. Syst. Sci. 31: 575-591

Streeter H W, Phelps E B 1925 A study of the pollution and natural purification of the Ohio River, III. Factors concerning the phenomena of oxidation and reaeration. U.S. Public Health Service, Pub. Health Bulletin No. 146, February, 1925. Reprinted by U.S., DHES, PHA, 1958.

Takyi A K, Lence B J 1994 Incorporating input information uncertainty in a water quality management model using combined simulation and optimization. Int. UNESCO Symp. on Water Resources Planning in a Changing World Karlsruhe, Germany

Takyi A K, Lence B J 1996 Chebyshev model for water-quality management. J. Water Resources Planning Manage., ASCE 122: 40-48

Takyi A K, Lence B J 1999 Surface water quality management using a multiple-realization chance constraint method. Water Resources Res. 35: 1657-1670

Wotton C L, Lence B J 1995 Risk-equivalent seasonal discharge programs for ice-covered rivers. $J$. Water Resources Planning Manage., ASCE 121: 275-282 